\title{
Using lithium as a neuroprotective agent in patients with cancer
}

\author{
Mustafa Khasraw ${ }^{1,2,3^{*}}$, David Ashley ${ }^{1,2}$, Greg Wheeler ${ }^{4}$ and Michael Berk ${ }^{1,25,6,7}$
}

\begin{abstract}
Neurocognitive impairment is being increasingly recognized as an important issue in patients with cancer who develop cognitive difficulties either as part of direct or indirect involvement of the nervous system or as a consequence of either chemotherapyrelated or radiotherapy-related complications. Brain radiotherapy in particular can lead to significant cognitive defects. Neurocognitive decline adversely affects quality of life, meaningful employment, and even simple daily activities. Neuroprotection may be a viable and realistic goal in preventing neurocognitive sequelae in these patients, especially in the setting of cranial irradiation. Lithium is an agent that has been in use for psychiatric disorders for decades, but recently there has been emerging evidence that it can have a neuroprotective effect.

This review discusses neurocognitive impairment in patients with cancer and the potential for investigating the use of lithium as a neuroprotectant in such patients.
\end{abstract}

\section{Introduction}

Cognitive changes are a documented consequence of cancer therapies, including chemotherapy and radiotherapy. Indeed, the ability to inhibit cell division, the key element in cancer therapies, causes reduction in neurogenesis, which is implicated in mood and cognitive disorders. Lithium is a mood stabilizer with known neuroprotective activity, a characteristic that is thought to underpin its therapeutic efficacy. In this review, we discuss preclinical and clinical studies investigating the possibility that lithium can ameliorate the neurocognitive deterioration seen in patients undergoing cancer treatment such as cranial irradiation and chemotherapy.

\footnotetext{
* Correspondence: m.khasraw@deakin.edu.au

${ }^{1}$ Andrew Love Cancer Centre, Geelong Hospital, Victoria, Australia

Full list of author information is available at the end of the article
}

The progress made in controlling systemic cancer is often hampered by relapse in the central nervous system (CNS). Systemic therapies, including both cytotoxic and biologic agents, do not achieve the same concentration in the CNS because of the blood-brain barrier. Consequently, there is a lower success rate for disease control in the CNS compared with extracranial areas. Metastatic and most primary brain tumors carry a dismal prognosis. Brain metastases are a devastating complication of cancer, and have been designated as an area of unmet need by the US Food and Drug Administration.

Radiotherapy is delivered to the brain for the palliative treatment of primary brain tumors and brain metastases, and also for treatment to prophylactically decrease the occurrence of CNS relapse in selected patients in diseases such as small cell lung cancer (SCLC) and certain hematological malignancies with known high rates of CNS relapse. Brain radiotherapy can lead to cognitive impairment and mood symptoms, which can further decrease quality of life in patients with limited expected survival. Chemotherapy drugs, such as doxorubicin, are similarly associated with cognitive side effects [1,2]. Patients who achieve long-term remission may struggle to return to normal life and functioning because of cognitive impairment.

\section{Neurocognitive impairment in patients with cancer}

In broad terms, brain tumor treatment is multimodal, with surgery, radiotherapy, and chemotherapy being involved. All three treatments may affect the neurocognitive outcomes [3]. In addition to its use in patients with cancer involving the CNS, brain radiotherapy is also used as prophylaxis in patients with limited stage SCLC who achieve good extracranial disease control.

\section{Chemotherapy and neurocognition}

'Chemo brain' has been studied in women with breast cancer, and also in other malignancies such as colon and non-small cell lung cancer (NSCLC). These studies seem to show a decline (sometimes transient) in cognitive function, after chemotherapy or haemopoietic stem-cell
C Biomed Central

C 2012 Khasraw et al; licensee BioMed Central Ltd. This is an Open Access article distributed under the terms of the Creative Commons Attribution License (http://creativecommons.org/licenses/by/2.0), which permits unrestricted use, distribution, and reproduction in any medium, provided the original work is properly cited. 
transplantation, particularly executive functions and short-term memory $[4,5]$. Using functional neuroimaging, abnormal activity of the frontal cortex, cerebellum, and basal ganglia has been shown in breast-cancer survivors as long as 5 to 10 years after chemotherapy [6]. Some studies with follow-up periods of more than 20 years show that women with breast cancer perform worse, on average, than random population controls on neuropsychological tests [7]. However, some patients may perform less well than controls even before chemotherapy. It is not known whether a component of the pre-treatment cognitive changes is paraneoplastic. Neuropsychological training may improve cognitive performance, [8] and pharmacologic intervention with agents such as modafinil may also be helpful [9].

Acute cognitive change induced by specific chemotherapy drugs is rare, with the exception of ifosfamide, which causes encephalopathy in approximately $12 \%$ of patients [10]. The delirium usually resolves within a few days. High-dose methotrexate may cause delirium with encephalopathy several days after the infusion, which lasts for a few days [11]. Indeed, methotrexate, whether given intravenously or intrathecally, is one of the few chemotherapeutic agents that cause significant cognitive dysfunction.

\section{Radiation and neurocognition}

Radiation mediates neurocognitive effects by affecting glial cells, neural stem and progenitor cells $[12,13]$, and the vascular structures $[14,15]$. Cranial irradiation delivered to mice has been shown to reduce neural proliferation, translating to long-term reduction in neurogenesis $[16,17]$. Reduction in neurogenesis is documented as a core component of the pathophysiology of depression and dementia, and many treatments for depression may promote neurogenesis[18]. Stress that can precipitate mood disorders can additionally produce neuronal atrophy and reduction of neurogenesis [19].

Radiotherapy is a significant factor in the neurocognitive decline of patients with cancer with brain metastases. Chronic changes in cognitive function not preceded by delirium can result from brain radiation, sometimes enhanced by chemotherapy, particularly with methotrexate [3].This is particularly evident in long-term survivors of radiosensitive malignancies, such as CNS lymphomas and some cases of SCLC.

Brain radiotherapy is commonly used as a palliative treatment for patients with brain metastases, but also in diseases with a relatively good prognosis, such as medulloblastoma, ependymoma, germinoma, and acute lymphoblastic leukemia. As mentioned above, prophylactic cranial irradiation is also used in certain clinical situations, such as with limited-disease SCLC and good extracranial response to therapy.
Acute encephalopathy may result from radiation with fractions of $300 \mathrm{cGy}$ or more to a large CNS treatment field. This can result in, or contribute to, other causes of delirium. Patients who have large tumors with increased intracranial pressure, and who are irradiated with high doses per fraction, may develop acute encephalopathy and even brain herniation after the initial few treatments [20]. Although there are no data from studies on this, corticosteroids are used in practice either to prevent or ameliorate symptoms.

Somnolence syndrome is a common intermediate side effect of cranial radiotherapy, which occurs approximately 6 weeks after treatment, and manifests as lethargy, increased sleepiness, poor attention or subtle memory changes, and altered temperament [21]. Somnolence syndrome occurs in approximately $60 \%$ of children treated with cranial irradiation for acute lymphatic leukemia, and in up to $80 \%$ of adults who are treated with cranial irradiation for brain tumors [22]. Somnolence syndrome usually occurs approximately 6 weeks after treatment, and manifests as lethargy, increased sleepiness, and poor attention or memory. There have been some reports of an associated fever [23]. In adults, the condition tends to be subtler, with memory changes and altered temperament. It is self-limiting, and does not seem to be linked to later sequelae. It is thought to be due to acute demyelination affecting neural signal transmission. Large doses of dexamethasone given during radiotherapy has been suggested to ameliorate this, but this is not routine practice [23].

Neurocognitive complications of cranial radiation are among the most distressing symptoms for patients, families, and care providers. In children who have craniospinal irradiation for medulloblastoma or germinoma, or more focal radiation for tumors such as ependymomas, gliomas, or craniopharyngiomas, the late effects are marked. Commonly, there is a decline in intelligence quotient (IQ) (full-scale, verbal and nonverbal domains), which tends to be more marked in patients who have a younger age at treatment; larger volumes of brain irradiated, particularly the temporal lobes; higher premorbid IQ; hydrocephalus requiring a shunt; and intrathecal chemotherapy in addition to radiotherapy. Children often have an initial improvement after the completion of therapy, but a later decline occurs 12 to 24 months later [4]. The decline clearly affects school completion and vocational achievements in later life. In older children, impaired short-term memory, processing speed, and shortened concentration span are common, and these problems progress with age.

The desire to reduce neurocognitive complications has driven many recent studies. Historically, children treated before the age of 2 years were often institutionalized because of their iatrogenic impairments. In both adults and children, dose, brain volume exposed, and fraction 
size are strong determinants of the outcomes. It is now well known that children receiving brain irradiation experience less severe neuropsychologic toxicity when treated with 23.4 Gy, rather than 36 Gy cranial irradiation, and that older children are less likely to develop cognitive impairment than children who are younger at the time of irradiation, suggesting greater vulnerability of the developing brain [24].

The use of cranial irradiation is linked to problems with long-term memory and concentration [15]. Modern radiotherapy techniques allow for sparing of sensitive areas of the CNS. Techniques such as intensity-modulated radiation therapy (IMRT) allow sparing of crucial structures such the optic chiasm or the pituitary gland. Sparing of the hippocampus, which has a crucial role in short-term memory, can also be achieved with the use of IMRT. This approach can still deliver acceptable target coverage and homogeneous delivery to the tumor area in the case of brain metastases [25]. Obviously, short-term memory is only one of the cognitive aspects affected by hippocampal damage. Exposure of other parts of the brain, such as the frontal and prefrontal cortex, may have a more subtle effect. Declines in attention, executive function, and motor, language, and general intellectual skills have been reported. Therefore, prospective well-controlled studies are needed to validate the role of hippocampal sparing. This question is currently under investigation in a randomized controlled phase II cooperative group trial to test the hypothesized neurocognitive benefit.

Additionally, there is a suggestion of a more rapid progression of dementing illness in patients receiving cranial irradiation, although the number of long-term survivors is limited [15]. There is also a risk of increased frequency of cerebrovascular accidents and small-vessel disease, thought to be due to intimal thickening of the cerebral arteries. Other late changes that can occur are the development of small cavernomas within the white matter, which may occasionally cause a low-pressure bleed, of little clinical significance.

Depression is another significant problem in this setting, and may be linked to reduction in neurogenesis. Indeed, it is possible to block the efficacy of antidepressants in some, but not all, models of antidepressant efficacy by impeding neurogenesis using cranial radiation [26]. This suggests that there are neurogenesis-dependent and neurogenesis-independent mechanisms of antidepressant action.

\section{Lithium and neurocognitive dysfunction}

Lithium is a standard part of the management of moderate to severe bipolar disorder and schizoaffective disorders, with a well-understood toxicity profile [27-29].

\section{Preclinical data on the neuroprotective effect of lithium (3)}

Lithium exerts neuroprotective effects and is associated with less cognitive loss in various brain-injury models, including after cranial irradiation [30,31]. In addition, neural stem/progenitor cells positively respond to lithium treatment under basal conditions [32,33]. In addition to evidence from animal studies, neuroimaging research in humans supports the observation that lithium exerts neuroprotective effects. One study used three-dimensional magnetic resonance imaging and brain segmentation to evaluate increases in the effect of lithium on grey-matter volume in patients with bipolar mood disorder. The use of 4 weeks of lithium treatment was shown to increase brain grey-matter content [34] and hippocampal volume [35]. The authors concluded that increases in grey matter probably occurred as a result of neurotrophic effects.

Lithium was found to protect irradiated hippocampal neurons in mice from apoptosis, resulting in better performance in learning and memory function [31]. Lithium is known to reduce oxidative stress, specifically via the glutathione system [36]. In bipolar disorder, lithium has been shown to prevent the loss of cortical grey matter that occurs as part of the neuroprogressive cascade in the disorder [37].

Whole-brain irradiation delivered to mice has been shown to reduce neural proliferation in the dentate gyrus subgranular zone, translating to long-term reduction in neurogenesis [38]. The number of neurons in the brain is controlled by production of new neurons and neuronal death. Glutamate, glucocorticoids, and haloperidol reduce neural progenitor proliferation in cerebellar granule cells [39], whereas lithium prevents the loss of proliferation induced by these agents. Microangiopathic and capillary loss in the treated areas, compounded by intimal thickening in the larger vessels, leads to reduction in vascularity and in white-matter damage [40,41].

Neural progenitor proliferation in the developing and adult brain plays a prominent role in the production of new neurons. One of the main targets of radiation to treat the observed neurocognitive effects seems to be the glial cells [42]. Oligodendrocyte loss in particular seems to affect the development of myelination of the damaged nerves [43]. Other major targets are neural stem and progenitor cells and the vascular structures [42]. Lithium increases the recovery of proliferating neural stem and progenitor cells in the dentate gyrus, and reduces the incidence of radiation-induced gliosis. In addition, neural stem and progenitor cells respond positively to lithium treatment under basal conditions [32] and in brain-injury models [33].

Lithium-induced neural progenitor proliferation in vitro suggests that similar effects might occur in vivo, and this action could also be related to its clinical efficacy 
[39]. In animal studies, the effect of lithium treatment is partly mediated by inhibiting inflammation and by promoting proliferation and survival of neural stem and progenitor cells [44]. Lithium was shown to increase progenitor, rather than stem-cell, proliferation in both non-ischemic and ischemic rat brains [44].

The nt/ $\beta$-Catenin pathway regulates cell-fate decisions during development in vertebrates and invertebrates. Glycogen synthase kinase (GSK)-3 has been shown to be an essential mediator of neural progenitors during brain development. The Wnt ligand is a secreted glycoprotein that binds to receptors, leading to displacement of the multifunctional kinase GSK-3 $\beta$ from the the adenomatous poliposis coli protein (APC)/axin/GSK-3 $\beta$ complex. In the absence of Wnt-signal (off-state), $\beta$-catenin, an integral cell-cell adhesion adaptor protein and transcriptional co-regulator, is targeted for degradation by the APC/axin/GSK-3 $\beta$-complex [45]. Lithium is an activator of $\beta$-catenin signaling, and may overcome inhibition of $\beta$-catenin signaling [46]. Lithium may also exert some of its neuroprotective actions via inhibition of GSK-3 $\beta$ [47]. Bcl-2 and Bax are apoptosis-related genes. Lithium induces a decrease in Bax protein levels and causes an increase in the Bcl-2/Bax ratio [48]. Long-term lithium treatment suppresses p53 and Bax expression, but increases Bcl-2 expression [48]. Activation of WNT signaling by lithium chloride, which inhibits the negative regulator of the $\mathrm{WNT} / \beta$-catenin pathway (GSK3 $\beta$ ), reduces astrocytic activation in neurodegenerative diseases, and is thought to do so through its ability to induce WNT signaling [46]. The neurotransmitter dopamine can exert its effects by acting on a lithium-sensitive signaling cascade involving Akt/PKB and GSK-3 [49]. In mouse striatum, lack of the dopamine transporter results in inactivation of Akt and concomitant activation of GSK- $3 \alpha$ and GSK-3 $\beta$, but these changes are effectively reversed by lithium [49]. Lithium additionally seems to block the excitotoxicity that is mediated by increased levels of intracellular calcium [50]. This is a pathway to apoptosis, [51-53] mediated by glutamate, and is a replicated finding in mood and cognitive disorders [54].

The Morris water maze (MWM) is a test of spatial learning for rodents, in which the rodents rely on distal cues to navigate from start locations around the perimeter of an open swimming arena to locate a submerged escape platform [55]. Lithium was found to protect irradiated hippocampal neurons in mice from apoptosis, resulting in better performance of rats in the MWM, reflecting better learning and memory function.

\section{Clinical data on the potential neuroprotective effect of lithium}

There are limited prospective clinical data on the use of lithium as a neuroprotectant. Several small imaging studies have shown that patients with bipolar disorder treated with long-term lithium therapy have fewer structural changes on brain imaging compared with patients with bipolar disorder of at least 2 years in duration who received lithium for less than 3 months. Patients with bipolar disorder who were not treated with lithium were found to have smaller left hippocampal volumes than controls (corrected $P<0.05$ ). The study included 17 patients with bipolar disorder who had at least 2 years of lithium therapy, compared with 12 patients with bipolar disorder who had less than 3 months of lifetime lithium exposure. The group treated with lithium had hippocampal volumes similar to those of 11 healthy controls and of young, lithium-naïve patients [56]. In a similar study, measurement of left prefrontal $\mathrm{N}$-acetyl aspartate (NAA) levels was performed using magnetic resonance spectroscopy at $1.5 \mathrm{~T}$. The study included 27 participants treated with lithium, 16 participants not treated with lithium ( $<3$ months exposure) and 21 healthy controls. The non-lithium group had lower prefrontal NAA levels than the lithium-treated group $(P<0.01)$ or control group $(P<0.05)$ [57].

In a large observational cohort study in Denmark, Kessing and colleagues showed that patients taking lithium were more likely than the general population to develop dementia; however, for those who continued to take lithium, the rates fell to those of the general population [58]. It is unclear whether this reflects drug effects, or is a proxy of disease-related effects, as people with mood disorders are at increased risk of developing dementia compared with the general population. This effect was not seen in the population taking anticonvulsants. A follow-up study published by the same group in 2010 showed that continued treatment with lithium was associated with a reduced rate of dementia in patients with bipolar disorder, in contrast to continued treatment with other drugs such as anticonvulsants, antidepressants, or antipsychotics [59]. A meta-analysis of lithium on cognitive performance found minor negative effects on cognition [60].

Long-term lithium treatment was also investigated in amnestic mild cognitive impairment as part of a study that randomized 45 participants to receive lithium ( 0.25 to 0.5 $\mathrm{mmol} / \mathrm{l})(\mathrm{n}=24)$ or placebo $(\mathrm{n}=21)$ in a double-blind trial [61]. Lithium treatment was associated with a significant decrease in CSF concentrations of P-tau ( $\mathrm{P}=0.03)$. Tau proteins are proteins that stabilize microtubules. When tau proteins are defective, and no longer stabilize microtubules properly, they can result in dementias. The study reported better performance on the cognitive subscale of the Alzheimer's Disease Assessment Scale and in attention tasks [61].

In an open-label study, the effects of administering lithium carbonate to patients with Alzheimer's disease 
for up to 1 year were evaluated [62]. No cognitive benefits were found in the patients who completed the study. In a different placebo-controlled, single-blind study, lithium was used to treat patients with mild Alzheimer's disease for 10 weeks. Lithium treatment was not found to have significant benefits on either cognitive performance or CSF concentrations of disease-related biomarkers [63].

There has been one early-phase study in which lithium was used as a neuroprotectant, which was presented in abstract form at the 2007 American Society for Therapeutic Radiology and Oncology [64], and updated at the 2008 annual meeting of the Society of Neuro-Oncology [65].

\section{Conclusions}

Neuroprotection may be a viable and realistic goal in preventing neurocognitive sequelae in patients with cancer, especially in the setting of cranial irradiation. There are two types of pathological processes amenable to intervention that could be targeted: 1) normal physiological processes that happen in excess, such as excitotoxicity, pruning. or excessive apoptotic activity [48] and 2) failure of trophic processes, such as reduced neurogenesis, senescence of progenitor cell generation, and differentiation. Such an approach would involve regulating the processes of growth and regeneration, and the rescue of brain cells that may be at risk of damage or even death [66].

Lithium is an agent that has been in use for psychiatric disorders for decades, providing us with a wealth of experience with this 'old' medication that has the potential for a novel indication. Nevertheless, there remain many unanswered questions. Because lithium may reduce free radical damage, which is one of the primary mechanisms of action for radiotherapy, it may reduce the efficacy of radiotherapy. There is also a theoretical concern that if the neural proliferating cells are stimulated during radiation treatment, this may actually increase the neural damage by reducing the repopulation pool.

In many studies of the biochemical and behavioral models, not only has lithium been found to be neuroprotective, but also antidepressants, atypical antipsychotics, and many substances such as vitamin A. However, none has shown a significant effect size in subsequent adequately powered human clinical trials for this indication. To date, there is no evidence that a pharmacological intervention could prevent or reduce radiation-induced somnolence syndrome or late neurocognitive impairment. In palliative patients, whose median survival may be measured in weeks, a significant proportion of survival time is affected by somnolence syndrome. Neurocognitive decline adversely affects quality of life, meaningful employment. and even simple daily activities $[67,68]$. Lithium has shown promise in preliminary studies, but if its benefit as a neuroprotectant in patients receiving cancer treatment is confirmed, it may ultimately lead to improvement in the quality of life for these patients.

\section{List of Abbreviations}

CNS: Central nervous system; CSF: Cerebrospinal fluid; GSK: Glycogen synthase kinase 3; IQ: Intelligence quotient; IMRT: Intensity-modulated radiation treatment; MWM: Morris Water Maze; NAA: N-acetyl aspartate; SCLC: Small-cell lung cancer

\section{Author details}

${ }^{1}$ Andrew Love Cancer Centre, Geelong Hospital, Victoria, Australia. ${ }^{2}$ School of Medicine of Deakin University, Geelong Victoria, Australia. ${ }^{3}$ Royal Melbourne Hospital, Parkville Victoria, Australia. ${ }^{4}$ Peter MacCallum Cancer Centre, Melbourne Victoria, Australia. ${ }^{5}$ Mental Health Research Institute, Parkville Victoria, Australia. ${ }^{6}$ Orygen Youth Health Research Centre and Centre for Youth Mental Health, Parkville, Victoria, Australia. ${ }^{7}$ Department of Psychiatry, University of Melbourne, Victoria, Australia.

\section{Authors' contributions}

MK and MB both conceived and designed the study, and wrote the manuscript. All the authors took part in the literature review. All the authors have read and approved the final manuscript.

\section{Competing Interests}

The authors have received grants from the Victoria Cancer Agency and The Viertel Charitable Foundation to undertake research investigating the neuroprotective effect of lithium in patients receiving cranial irradiation.

Received: 10 July 2012 Accepted: 2 November 2012

Published: 2 November 2012

\section{References}

1. Aluise CD, Sultana R, Tangpong J, Vore M, St Clair D, Moscow JA, Butterfield DA: Chemo brain (chemo fog) as a potential side effect of doxorubicin administration: role of cytokine-induced, oxidative/ nitrosative stress in cognitive dysfunction. Adv Exp Med Biol 2010, 678:147-156.

2. Taillibert S: Is systemic anti-cancer therapy neurotoxic? Does chemobrain exist? and should we rename it? Adv Exp Med Biol 2010, 678:86-95.

3. Khasraw M, Posner JB: Neurological complications of systemic cancer. Lancet Neurol 2010, 9(12):1214-1227.

4. Chang G, Meadows ME, Orav EJ, Antin JH: Mental status changes after hematopoietic stem cell transplantation. Cancer 2009, 115(19):4625-4635.

5. Vardy J, Rourke S, Tannock IF: Evaluation of cognitive function associated with chemotherapy: a review of published studies and recommendations for future research. J Clin Oncol 2007, 25(17):2455-2463.

6. Silverman DH, Dy CJ, Castellon SA, Lai J, Pio BS, Abraham L, Waddell K, Petersen L, Phelps ME, Ganz PA: Altered frontocortical, cerebellar, and basal ganglia activity in adjuvant-treated breast cancer survivors 5-10 years after chemotherapy. Breast Cancer Res Treat 2007, 103(3):303-311.

7. Koppelmans V, Breteler MMB, Boogerd W, Seynaeve C, Gundy C, Schagen SB: Neuropsychological performance in survivors of breast cancer more than 20 years after adjuvant chemotherapy. Journal of Clinical Oncology 2012, 30(10):1080-1086.

8. Poppelreuter M, Weis J, Bartsch $\mathrm{HH}$ : Effects of specific neuropsychological training programs for breast cancer patients after adjuvant chemotherapy. J Psychosoc Oncol 2009, 27(2):274-296.

9. Kohli S, Fisher SG, Tra Y, Adams MJ, Mapstone ME, Wesnes KA, Roscoe JA, Morrow GR: The effect of modafinil on cognitive function in breast cancer survivors. Cancer 2009, 115(12):2605-2616.

10. Ajithkumar T, Parkinson C, Shamshad F, Murray P: Ifosfamide encephalopathy. Clin Oncol (R Coll Radiol) 2007, 19(2):108-114.

11. Inaba H, Khan RB, Laningham FH, Crews KR, Pui CH, Daw NC: Clinical and radiological characteristics of methotrexate-induced acute encephalopathy in pediatric patients with cancer. Ann Oncol 2008, 19(1):178-184.

12. Monje $M L$, Vogel $H$, Masek M, Ligon KL, Fisher PG, Palmer TD: Impaired human hippocampal neurogenesis after treatment for central nervous system malignancies. Ann Neurol 2007, 62(5):515-520. 
13. Monje ML, Palmer T: Radiation injury and neurogenesis. Curr Opin Neuro 2003, 16(2):129-134.

14. Perry A, Schmidt RE: Cancer therapy-associated CNS neuropathology: an update and review of the literature. Acta Neuropathol 2006, 111(3):197-212.

15. Armstrong CL, Gyato K, Awadalla AW, Lustig R, Tochner ZA: A critical review of the clinical effects of therapeutic irradiation damage to the brain: the roots of controversy. Neuropsychol Rev 2004, 14(1):65-86.

16. Rola R, Raber J, Rizk A, Otsuka S, VandenBerg SR, Morhardt DR, Fike JR: Radiation-induced impairment of hippocampal neurogenesis is associated with cognitive deficits in young mice. Exp Neurol 2004 188(2):316-330.

17. Vorhees CV, Williams MT: Morris water maze: procedures for assessing spatial and related forms of learning and memory. Nat Protoc 2006, 1(2):848-858.

18. Moylan S, Maes M, Wray N, Berk M: The neuroprogressive nature of major depressive disorder: pathways to disease evolution and resistance, and therapeutic implications. Mol Psychiatry 2012.

19. Duman RS, Monteggia LM: A neurotrophic model for stress-related mood disorders. Biol Psychiatry 2006, 59(12):1116-1127.

20. Young DF, Posner JB, Chu F, Nisce L: Rapid-course radiation therapy of cerebral metastases: results and complications. Cancer 1974, 34(4):1069-1076.

21. Kelsey CR, Marks LB: Somnolence syndrome after focal radiation therapy to the pineal region: case report and review of the literature. $J$ Neurooncol 2006, 78(2):153-156.

22. Faithfull S, Brada M: Somnolence syndrome in adults following cranial irradiation for primary brain tumours. Clinical Oncology 1998, 10(4):250-254

23. Kelsey CR, Marks LB: Somnolence syndrome after focal radiation therapy to the pineal region: case report and review of the literature. Journal of neuro-oncology 2006, 78(2):153-156.

24. Mulhern RK, Kepner JL, Thomas PR, Armstrong FD, Friedman HS, Kun LE: Neuropsychologic functioning of survivors of childhood medulloblastoma randomized to receive conventional or reduced-dose craniospinal irradiation: a Pediatric Oncology Group study. J Clin Oncol 1998, 16(5):1723-1728.

25. Gondi V, Tolakanahalli R, Mehta MP, Tewatia D, Rowley H, Kuo JS, Khuntia D, Tom WA: Hippocampal-sparing whole-brain radiotherapy: A "how-to" technique using helical tomotherapy and linear acceleratorbased intensity-modulated radiotherapy. Int J Radiat Oncol Biol Phys 2010, 78(4):1244-1252

26. David DJ, Samuels BA, Rainer Q, Wang JW, Marsteller D, Mendez I, Drew M, Craig DA, Guiard BP, Guilloux JP: Neurogenesis-dependent andindependent effects of fluoxetine in an animal model of anxiety/ depression. Neuron 2009, 62(4):479-493.

27. Malhi GS, Tanious M, Das P, Berk M: The science and practice of lithium therapy. Aus N Z J Psychiatry 2012, 46(3):192-211.

28. Malhi GS, Adams D, Berk M: Is lithium in a class of its own? A brief profile of its clinical use. Aus N Z J Psychiatry 2009, 43(12):1096-1104.

29. Malhi GS, Berk M: Is the safety of lithium no longer in the balance? Lancet 2012.

30. Rowe MK, Chuang DM: Lithium neuroprotection: molecular mechanisms and clinical implications. Expert Rev Mol Med 2004, 6(21):1-18.

31. Yazlovitskaya EM, Edwards E, Thotala D, Fu A, Osusky KL, Whetsell WO, Boone B, Shinohara ET, Hallahan DE: Lithium treatment prevents neurocognitive deficit resulting from cranial irradiation. Cancer Res 2006, 66(23):11179-11186

32. Chen G, Rajkowska G, Du F, Seraji-Bozorgzad N, Manji HK: Enhancement of hippocampal neurogenesis by lithium. J Neurochem 2000, 75(4):1729-1734

33. Yan XB, Hou HL, Wu LM, Liu J, Zhou JN: Lithium regulates hippocampal neurogenesis by ERK pathway and facilitates recovery of spatial learning and memory in rats after transient global cerebral ischemia. Neuropharmacology 2007, 53(4):487-495

34. Moore GJ, Bebchuk JM, Wilds IB, Chen G, Manji HK: Lithium-induced increase in human brain grey matter. Lancet 2000, 356(9237):1241-1242.

35. Foland LC, Altshuler LL, Sugar CA, Lee AD, Leow AD, Townsend J, Narr KL, Asuncion DM, Toga AW, Thompson PM: Increased volume of the amygdala and hippocampus in bipolar patients treated with lithium. Neuroreport 2008, 19(2):221-224.
36. Machado-Vieira R, Andreazza AC, Viale Cl, Zanatto V, Cereser V, Vargas RS, Kapczinski F, Portela LV, Souza DO, Salvador M: Oxidative stress parameters in unmedicated and treated bipolar subjects during initial manic episode: a possible role for lithium antioxidant effects. Neurosci Lett 2007, 421(1):33-36.

37. Serap Monkul E, Malhi GS, Soares JC: Anatomical MRI Abnormalities in bipolar disorder: do they exist and do they progress? Australian and New Zealand Journal of Psychiatry 2005, 39(4):222-226.

38. Rola R, Raber J, Rizk A, Otsuka S, VandenBerg SR, Morhardt DR, Fike JR: Radiation-induced impairment of hippocampal neurogenesis is associated with cognitive deficits in young mice. Exp neurol 2004, 188(2):316-330.

39. Hashimoto R, Senatorov V, Kanai H, Leeds P, Chuang DM: Lithium stimulates progenitor proliferation in cultured brain neurons. Neuroscience 2003, 117(1):55-61.

40. Brown WR, Thore CR, Moody DM, Robbins ME, Wheeler KT: Vascular damage after fractionated whole-brain irradiation in rats. Radiat Res 2005 , 164(5):662-668.

41. Coderre JA, Morris GM, Micca PL, Hopewell JW, Verhagen I, Kleiboer BJ, van der Kogel AJ: Late effects of radiation on the central nervous system: role of vascular endothelial damage and glial stem cell survival. Radiat Res 2006, 166(3):495-503

42. Andres-Mach M, Rola R, Fike JR: Radiation effects on neural precursor cells in the dentate gyrus. Cell Tiss Res 2008, 331(1):251-262.

43. Panagiotakos G, Alshamy G, Chan B, Abrams R, Greenberg E, Saxena A, Bradbury M, Edgar M, Gutin P, Tabar V: Long-term impact of radiation on the stem cell and oligodendrocyte precursors in the brain. PloS one 2007, 2(7):e588.

44. Lai A, Tran A, Nghiemphu PL, Pope WB, Solis OE, Selch M, Filka E, Yong WH, Mischel PS, Liau LM, et al: Phase II study of bevacizumab plus temozolomide during and after radiation therapy for patients with newly diagnosed glioblastoma multiforme. J Clin Oncol 2011, 29(2):142-148.

45. MacDonald BT, Tamai K, He X: Wnt/catenin signaling: components, mechanisms, and diseases. Dev Cell 2009, 17(1):9-26.

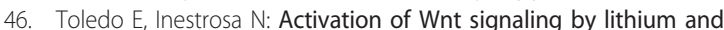
rosiglitazone reduced spatial memory impairment and neurodegeneration in brains of an APPswe/PSEN1CFîE9 mouse model of Alzheimer's disease. Mol Psychiatry 2009, 15(3):272-285.

47. Gould TD, Manji HK: Glycogen synthase kinase-3: a putative molecular target for lithium mimetic drugs. Neuropsychopharmacology 2005, 30(7):1223-1237

48. Chuang DM, Chen RW, Chalecka, Franaszek E, Ren M, Hashimoto R, Senatorov V, Kanai H, Hough C, Hiroi T, Leeds P: Neuroprotective effects of lithium in cultured cells and animal models of diseases. Bipolar disorders 2002, 4(2):129-136

49. Beaulieu J-M, Sotnikova TD, Yao W-D, Kockeritz L, Woodgett JR, Gainetdinov RR, Caron MG: Lithium antagonizes dopamine-dependent behaviors mediated by an AKT/glycogen synthase kinase 3 signaling cascade. Proc Natl Acad Sci USA 2004, 101(14):5099-5104.

50. Berk $M$, Kirchmann NH, Butkow N: Lithium blocks $45 \mathrm{Ca} 2+$ uptake into platelets in bipolar affective disorder and controls. Clin Neuropharmacol 1996, 19(1):48.

51. Maes M, Fisar Z, Medina M, Scapagnini G, Nowak G, Berk M: New drug targets in depression: inflammatory, cell-mediated immune, oxidative and nitrosative stress, mitochondrial, antioxidant, and neuroprogressive pathways. And new drug candidates, ÄîNrf2 activators and GSK-3 inhibitors. Inflammopharmacology 2012, 1-24.

52. Berk M, Plein $H$, Ferreira D: Platelet glutamate receptor supersensitivity in major depressive disorder. Clin Neuropharmacol 2001, 24(3):129.

53. Berk M, Plein H, Belsham B: The specificity of platelet glutamate receptor supersensitivity in psychotic disorders. Life Sci 2000, 66(25):2427-2432.

54. Plein $\mathrm{H}$, Berk M: The platelet as a peripheral marker in psychiatric illness. Clin Exp Pharmacol 2001, 16(3):229-236.

55. Vorhees CV, Williams MT: Morris water maze: procedures for assessing spatial and related forms of learning and memory. Nature protocols 2006, 1(2):848-858

56. Hajek T, Cullis J, Novak T, Kopecek M, Haschl C, Blagdon R, O'Donovan C, Bauer M, Young LT, MacQueen G: Hippocampal volumes in bipolar disorders: opposing effects of illness burden and lithium treatment. Bipolar disord 2012, 14(3):261-270. 
57. Hajek T, Bauer M, Pfennig A, Cullis J, Ploch J, O,Donovan C, Bohner G, Klingebiel R, Young LT, MacQueen GM: Large positive effect of lithium on prefrontal cortex $\mathrm{N}$-acetylaspartate in patients with bipolar disorder: 2-centre study. 2012.

58. Kessing LV, Sondergard L, Forman JL, Andersen PK: Lithium treatment and risk of dementia. Arch Gen Psychiatry 2008, 65(11):1331-1335.

59. Kessing LV, Forman JL, Andersen PK: Does lithium protect against dementia? Bipolar disord 2010, 12(1):87-94.

60. Wingo AP, Wingo TS, Harvey PD, Baldessarini RJ: Effects of lithium on cognitive performance: a meta-analysis. J Clin Psychiatry 2009, 70(11):1588-1597.

61. Forlenza OV, Diniz BS, Radanovic M, Santos FS, Talib LL, Gattaz WF: Diseasemodifying properties of long-term lithium treatment for amnestic mild cognitive impairment: randomised controlled trial. Br J Psychiatry 2011, 198(5):351-356.

62. Macdonald A, Briggs K, Poppe M, Higgins A, Velayudhan L, Lovestone S: A feasibility and tolerability study of lithium in Alzheimer's disease. Int J Ger Psychiatry 2008, 23(7):704-711.

63. Hampel H, Ewers M, Burger K, Annas P, Mortberg A, Bogstedt A, Frolich L, Schroder J, Schonknecht P, Riepe MW: Lithium trial in Alzheimer's disease: a randomized, single-blind, placebo-controlled, multicenter 10-week study. J Clinical Psychiatry 2010, 70(6):922.

64. Yang ES, Lu, B., Hallahan, D.E.: Lithium-mediated neuroprotection during cranial irradiation: A phase 1 trial. ASTRO (American Society for Therapeutic Radiology and Oncology) - 49th annual Conference Los Angeles CA; 2007.

65. Xia F, Yang E, Hallahan D, Lu B: Lithium-mediated neuroprotection during cranial irradiation: a phase I trial. Neuro-oncology 2008, 10(5):887-887.

66. Fukuda H, Fukuda A, Zhu C, Korhonen L, Swanpalmer J, Hertzman S, Leist M, Lannering B, Lindholm D, Bj/ark-Eriksson T: Irradiation-induced progenitor cell death in the developing brain is resistant to erythropoietin treatment and caspase inhibition. Cell Death Differ 2004, 11(11):1166-1178.

67. Marko NF, Weil RJ: Radiotherapy: neurocognitive considerations in the treatment of brain metastases. Nat Rev Clin Oncol 2010, 7(4):185-186.

68. Khasraw M, Lassman AB: Neuro-oncology: late neurocognitive decline after radiotherapy for low-grade glioma. Nat Rev Neurol 2009, 5(12):646-647.

\section{Pre-publication history}

The pre-publication history for this paper can be accessed here: http://www.biomedcentral.com/1741-7015/10/131/prepub

doi:10.1186/1741-7015-10-131

Cite this article as: Khasraw et al:: Using lithium as a neuroprotective agent in patients with cancer. BMC Medicine 2012 10:131.

\section{Submit your next manuscript to BioMed Central and take full advantage of:}

- Convenient online submission

- Thorough peer review

- No space constraints or color figure charges

- Immediate publication on acceptance

- Inclusion in PubMed, CAS, Scopus and Google Scholar

- Research which is freely available for redistribution

Submit your manuscript at www.biomedcentral.com/submit
Biomed Central 